\title{
Entrepreneurship
}

Jan a Jun $2021-\mathrm{v} .5-\mathrm{n} .1$

ISSN: 2595-4318

This article is also available online at: www.sustenere.co

\section{Morfologia urbana: a segregação na cidade contemporânea}

O objetivo desse trabalho é realizar uma revisão teórica da segregação consolidada no solo urbano. Além de trazer uma breve abordagem histórica do termo segregação, se encontra entre as questões analisadas, os aspectos relacionados as causas dessa ruptura e ao mesmo tempo, elucidar as causas e consequências do agrupamento de semelhantes em comunidades, sejam elas carentes ou mesmo em condomínios residências de alto padrão, bem como, compreender o comportamento dos mesmos em relação ao entorno dos agrupamentos, seja no perímetro imediato ou em relação a toda a cidade. Como resultado, foi possível elencar os agentes desse fenômeno, como, o poder monetário ou a falta dele advindo do fator capitalista do mercado financeiro vigente, a atuação do mercado imobiliário na transformação do solo das cidades em mercadorias e as políticas públicas voltadas para as questões relacionadas ao planejamento urbano, a moradia e a morfologia urbana.

Palavras-chave: Segregação; Cidades contemporâneas; Morfologia urbana.

\section{Urban morphology: segregation in the contemporary city}

The objective of this work is to carry out a theoretical review of the consolidated segregation in urban soil. In addition to bringing a brief historical approach to the term segregation, among the issues analyzed are aspects related to the causes of this rupture and, at the same time, elucidating the causes and consequences of grouping similars in communities, whether they are needy or even in residential condominiums. High standard, as well as, understand their behavior in relation to the surroundings of the groupings, either in the immediate perimeter or in relation to the whole city. As a result, it was possible to list the agents of this phenomenon, such as, the monetary power or the lack of it arising from the capitalist factor of the current financial market, the performance of the real estate market in the transformation of the cities' soil into commodities and public policies focused on the issues related to urban planning, housing and urban morphology.

Keywords: Segregation; Contemporary cities; Urban morphology.

Topic: Planejamento Urbano

Reviewed anonymously in the process of blind peer
Received: 20/02/2021

Approved: 22/05/2021
Marcelo Ferreira da Silva Salla (iD

Universidade do Oeste de Santa Catarina, Brasil

http://lattes.cnpq.br/0522527936329663

http://orcid.org/0000-0003-4099-0486

sallamarcelo@outlook.com

Anderson Saccol Ferreira (iD

Universidade do Oeste de Santa Catarina, Brasil

http://lattes.cnpq.br/4850843904897537

http://orcid.org/0000-0002-6237-9912

anderson.ferreira@unoesc.edu.br

\section{Referencing this:}

SALLA, M. F. S.; FERREIRA, A. S.. Morfologia urbana: a segregação na cidade contemporânea. Entrepreneurship, v.5, n.1, p.48-56, 2021. DOI: http://doi.org/10.6008/CBPC2595-4318.2021.001.0005 


\section{INTRODUÇÃO}

A cidade contemporânea, é o local onde vivemos, convivemos, trabalhamos e exercemos as mais diversas funções sociais. É aqui, nesse contexto socioespacial diversos e heterogêneo que se encontram um dos maiores desafios, compreender a formação de uma sociedade mais plural, onde as problemáticas sociais se tornam interdependentes em contextos urbanos cada vez mais fragmentados. O Brasil por sua vez, enfrenta o desafio de superar os paradigmas deixados pelo urbanismo modernista, e desde sua redemocratização no final dos anos de 1980, vem buscando maneiras de resolver a problemática de uma sociedade mais justa e igualitária em um contexto "historicamente desequilibrado" (DEL RIO et al., 2019).

E essa escala de divisão interna de uma cidade, embora em novos contextos, não é algo novo. Para Sposito (2018), essas diferenças socioespaciais são uma marca presente desde as primeiras formações urbanas, e apresentam íntima relação com o trabalho que cada pessoa exerce na sociedade. Vasconcelos (2016), alerta que tais diferenças sociais resultantes da formação dos espaços urbanos se diferem em cada parte do globo. O Brasil tem as suas próprias particularidades que levam a vários fenômenos urbanos, sendo um deles, a segregação sócio espacial.

A hipótese de que fenômenos urbanos como a própria morfologia urbana tem relação íntima com o trabalho exercido pelas pessoas, uma vez que a função de trabalho desempenhada exerce analogia com a capacidade de ganho material, nesse caso, a segregação urbana seria um fenômeno exclusivo do mercado capital? Existem ainda outros fatores, como políticos e sociais capazes de exercerem direta ou indiretamente a divisão territorial segregada, seja por políticas sociais, obras públicas ou mesmo por vontade própria?

O objetivo desse estudo é realizar uma revisão teórica da segregação consolidada no solo urbano. Com uma gama de estudos relacionados a este tema no Brasil, este artigo busca uma revisão teórica que visa elucidar diversos aspectos em que a segregação é vislumbrada nos mais distintos traçados urbanos das cidades, e dessa forma, analisar os meios pelo qual esse efeito acontece e perdura, sendo possível contrapor diferentes linhas de pesquisa e pensamentos teóricos e complementando-os mutuamente, formando assim um panorama sobre o atual momento em que vivem as cidades com seus aspectos de segregação urbana, bem como, seus antecedentes históricos.

É esta realidade que irá ser analisada, afim de se identificar os fatores que levam à segregação, pois como lembra Corrêa (2016), este é um processo que expõe a noção de diferentes classes no território urbano, ou seja, são espaços que apresentam homogeneidade aos que o compõem, porém são heterogêneos aos espaços restantes, isso faz com que seja necessário um estudo mais aprofundado que possa elucidar como estes grupos se comportam, e qual é o fator de união entre estas diferentes massas, bem como qual a relação que as mesmas exercem para com a cidade. Além dessa introdução esse trabalho se divide em segregação urbana: causas e consequências, principais resultados e considerações finais. 


\section{REVISÃO TEÓRICA}

\section{Segregação urbana: causas e consequências}

Segundo a definição do Dicionário de Sinônimos da Língua Portuguesa Pombo (2011), a palavra segregação exprime a ideia de "separar, afastar, destacar uma coisa da outra", desunindo-as e pondo-as a parte uma da outra, ou seja, a palavra manifesta o ato da separação em duas ou mais partes de algo, expondo assim uma em contraposição à outra, podendo dessa forma resultar em desunião, desarmonia e desigualdade entre as partes segregadas.

Em seu contexto histórico, a palavra segregação denota de processos que resultaram em grandes transformações sociais. De acordo com Vasconcelos (2016), a origem do termo deu-se do latim segrego, aquilo que se cerca, desde de então, muitos processos históricos culminaram na segregação de partes da população, sendo de fato os mais notáveis, a criação dos guettos para alocar os judeus, tanto em Veneza durante o período da Republica, quanto os criados durante a segunda guerra, baseados na ideologia do nazismo, e também, a política de segregação racial norte americana que resultou na criação de espaços delimitados de uso para a população negra.

Embora a etimologia da palavra tenha forte ligação com eventos históricos, existe uma divergência entre autores quanto ao uso do termo. O próprio Vasconcelos (2016), alerta que é importante se manter fiel a origem do termo, para que o mesmo não perca o seu "caráter heurístico" quando usado de maneira generalizada. Mas ao mesmo tempo, Sposito (2016) lembra que conceitos mudam com o passar dos anos, a acabam se adaptando a questões relacionadas a problemas atuais, não sendo diferente ao conceito de segregação urbana.

Para que seja possível analisar os fatores responsáveis pela segregação espacial, primeiro é preciso entender em que aspectos tal fenômeno ocorre, ou seja, a formação morfológica das cidades que é a protagonista do feito. Embora não seja objeto direto dessa pesquisa, é preciso abranger o aspecto capitalista de produção do espaço, afinal, a expansão tanto do tecido urbano quando da densidade construtiva tem íntima relação com o valor monetário praticado (MOREIRA JÚNIOR, 2010). Dessa forma, a cidade se constitui como um artifício exclusivo da ação humana que é a responsável pela concepção dos espaços (MOREIRA JÚNIOR, 2010).

Partindo desse princípio de que a cidade é fruto da ação do homem e de que sem capital não seria possível a modificação do espaço. Carlos (2018) revela que um dos produtos do capitalismo, o solo urbano, segundo as suas palavras, "[...] realizou a generalização do espaço como propriedade privada[...]", dessa forma, a segregação entre classes se aprofunda, uma vez que a condicionante de se obter um espaço urbano habitável é o resultado do poder de compra do indivíduo, mesmo quando o território é redigido por regulamentos do Estado, "[...] criando a contradição entre o espaço produzido enquanto valor de uso e o espaço produzido enquanto valor de troca, com a separação radical entre espaço público e privado e aprofundamento da segregação[...]" (CARLOS, 2018).

Para que se possa compreender esse efeito, Ribeiro (2018), faz uma crítica mais profunda, alertando- 
nos que no Brasil a produção espacial é calcada na extrema desigualdade, fruto de fatores históricos de uma cultura autoritária, e que parece ter sido absorvido de maneira pacífica pela sociedade, e hoje as cidades não escondem em suas paisagens as mazelas desse feito, fazendo deste território um local perfeito para tal reprodução desigual que perdura, sendo um fator mútuo e complementar, onde a criação de novos espaços acaba por contribuir para o aprofundamento da desigualdade, marcando o território por meio de um subproduto desse processo.

E em meio a esses fatores, a condição social é apontada como uma das condicionantes de um processo presente no território urbano que independe de sua localização, a ilegalidade territorial. Nesse processo, pobreza e inadequação territorial se unem, formado assim glebas urbanas à margem da urbanização, gerando uma ruptura socioespacial em determinados locais da cidade. As denominadas "favelas", acabam por criar uma nova tessitura na cidade, um novo modo de ocupar o espaço, tanto que seus moradores preferem o termo "comunidade", referindo-se ao espaço como algo homogêneo, um espaço de identidade coletiva (LAGO, 2003).

Essa forma de separação em camadas da sociedade, tem forte e íntima relação com a produção do espaço que é guiado pelo poder de compra. Na concepção do espaço da cidade capitalista, a divisão de classes se evidencia na ocupação territorial, formando assim espaços que se destinam ou não ao uso de determinadas "classes dominantes" (CANETTIERI et al., 2017). Nessa ótica, resulta em uma cidade em que o poder de compra é que determina não só o espaço mas também o local a ser ocupado, muitas vezes forçando pessoas de baixo rendimento a ocuparem-se de locais cada vez mais distante dos centros, ou mesmo compelidos ao fazerem, quando políticas públicas muitas vezes por meio de interesses privados, forçam a retirada de moradores de locais de ocupação irregular, frequentemente bem localizados, limitando-os a uma nova ocupação de um espaço pré-determinado, ou seja, amiúde mal localizados (CANETTIERI et al., 2017). É com maior clareza que se demonstra o motivo da união de pessoas em comunidades, uma vez que esse processo é um reflexo da divisão de classes sociais que por sua vez fica estampado na malha urbana, que acaba por refletir essa divisão.

E se a falta de recursos financeiros força a união de pessoas semelhantes em grupos, o mesmo fenômeno é observado nas classes de mais abastadas. No mercado imobiliário vem a ser chamado de condomínios residências fechadas, sendo que nesse estudo de maneira mais enfática, levasse em conta a proliferação dos condomínios fechados horizontais. Essa nova forma de morar expressa uma nova maneira de segregar o espaço urbano, e vai mais além, esse estilo de vida acaba por romper um fator antes dominante no cenário das cidades, o centro rico versus a periferia pobre, que agora passa a vislumbrar um novo modelo de desigualdade (MEDEIROS et al., 2008). A periferia que por sua natureza dispõe de um espaço mais amplo que o centro já não oferece, passa agora a ser um local de vislumbre das classes de maior poder econômico, que possuem as condições necessárias para "consumir" este espaço (MEDEIROS et al., 2008).

Esses espaços surgem com a promessa de um "novo modo de viver", dentro de seu espaço murado, nega a vida externa na cidade, e cria um ambiente capaz de satisfazer todas as necessidades de seus moradores. Dentro de seu recinto vigiado e controlado, são oferecidas todas as benesses de se viver de 
maneira alheia à cidade, praças, equipamentos de ginástica, natação, serviços de lavanderia, motoristas, entre outros, se juntam ao apelo pela segurança, um dos principais fatores relacionados aos empreendimentos, ou seja, a garantia de que o local oferece os benefícios de se viver em uma cidade, mas de maneira abstrata e segregada, protegida por muros e guaritas que controlam a entrada e acabam por negar o seu entorno (PADUA, 2018).

O fenômeno de agrupamento por questões sociais, raciais e religiosas, sempre foi um fato histórico, como já visto desde a formação dos guettos, mas como lembra Frey et al. (2006), o fator econômico atua com maior poder de influência quando o assunto é a segregação no Brasil, esse novo modelo em que é proposital essa separação territorial presente nos condomínios vem sendo chamada de auto segregação, uma vez que é por livre escolha que os indivíduos optam pelo isolamento (FREY et al., 2006). É de maneira mais recente que tais condomínios dominaram o imaginário da população, sendo objeto de desejo não somente das classes de maior poder aquisitivo da classe média no país. Pádua (2018, p. 89) propõem “uma vida na qual se precisa o menos possível sair do condomínio, pois ele satisfaz grande parte das necessidades cotidiana dos moradores, logicamente com um custo adicional para esses serviços".

Ciente desse desejo crescente por parte da classe menos abastada de se apropriar dessa condição que os condomínios fechados oferecem, grandes incorporadoras se apropriaram desse apelo, criando os condomínios populares que atendem as demandas do programa de moradia popular Minha Casa Minha Vida (MCMV), replicando-os em grandes glebas, com extremo distanciamento das áreas urbanas consolidadas, sob argumentação de que somente nestes locais é possível equilibrar o custo de terreno e o custo da construção, para assim oferecer ao consumidor final um imóvel que atenda aos parâmetros de poder de compra dessa categoria de menor rendimento médio mensal (FERREIRA, 2012).

E se tratando do poder público, Hirata (2009), alerta que políticas públicas sociais, como as do programa Minha Casa Minha Vida - MCMV ou de seus antecessores, acabam por estimular essa postura adotada pelo mercado imobiliário. Cria-se um discurso baseado na qualidade de vida e na necessidade de se construir em novos espaços em que se mitigue os efeitos causados pela urbanização, mas na prática não se delimitam com clareza nos planos e nas leis, instrumentos capazes de inibirem a atuação desenfreada do mercado imobiliário, que acaba assumindo o protagonismo frente a disputada pelo espaço urbano, causando assim a falta de capacidade de que tais pessoas decidam onde vão morar, o que na prática significa que as pessoas precisam dobrar-se a vontade que lhes é imposta e adaptar-se à condição de moradia, impedindoas de usufruírem melhores espaços nas cidades.

E a falta de escolha sobre o local de moradia expõe o problema de segregação desses condomínios populares que acabam sendo implantados nas "franjas urbanas" das cidades, trazendo à tona outros problemas, como a dificuldade de inserção e de mobilidade urbana. Embora haja engajamento por parte de arquitetos, nesses casos, o lucro se impõem de maneira a se sobrepor as questões de qualidade arquitetônicas e urbanas, atendendo tão somente aos interesses pautados no ganho material. Ao reproduzir de maneira ilógica o padrão residencial condominial tão apreciado pelas classes de maior poder aquisitivo, a cidade caminha de maneira contrária à sustentabilidade urbana, e coopera para a perpetuação de um 
modelo segregacionista de criação de espaços (FERREIRA, 2012).

\section{METODOLOGIA}

O uso de documentos na pesquisa busca valorizar a riqueza de informações que podem ser extraídas, ampliando o entendimento dos objetivos, cuja compreensão necessite de contextualização histórica e sociocultural. Dessa forma, a pesquisa documental investigar os documentos que ainda não sofreram nenhum tratamento analítico e que possam ser reelaborados de acordo com os objetivos da pesquisa (HELDER, 2006).

Para Cellard, (2008, p. 295), "[...] o documento escrito constitui uma fonte extremamente preciosa para todo pesquisador [...] ele é, evidentemente, insubstituível em qualquer reconstituição referente a um passado relativamente distante [...]" O qual permitiu realizar uma abordagem dos aspectos históricos do termo segregação urbana e quais aspectos causam a ruptura temporal de forma a elucidar as causas e consequências do agrupamento de semelhantes em comunidades carentes ou residentes em edificações de alto padrão. Nas plataformas CAPES com a palavra-chave "Segregação urbana" encontramos 529 periódicos, tabulados conforme o quadro 1.

Quadro 1: Informações para tabulação de dados pretextais

\begin{tabular}{|l|l|l|l|}
\hline Identificação & Informações pretextais & Método de pesquisa & Conclusões \\
\hline Titulo & $\begin{array}{l}\text { Objetivo Geral do Estudo/ Palavras- } \\
\text { chaves }\end{array}$ & Tipo de estudo & Limitadores da Pesquisa \\
\hline Autor & Principais Resultados & Indicadores de segregação & Contribuição Teórica do Estudo \\
\hline Ano & Principais autores & $\begin{array}{l}\text { Benefícios relacionado com a teria e } \\
\text { pratica }\end{array}$ & $\begin{array}{l}\text { Recomendações para futuros } \\
\text { estudos }\end{array}$ \\
\hline
\end{tabular}

Os dados foram coletados seguindo os critérios avaliativos, identificação, informações pretextais, método de pesquisa e conclusões. Após a tabulados dos dados foi realizado a análise dos aspectos que tratam da segregação urbana de forma a gerar a compreensão do espaço urbano coletivo, justo e igualitário.

\section{RESULTADOS E DISCUSSÃO}

A segregação urbana é fruto de fatores diversos, mas que convergem em um ponto comum, o poder de compra de cada indivíduo, e de como o capitalismo é capaz de modificar o meio urbano. Para Sposito (2018), isto é perceptível quando grandes glebas antes rurais e agora urbanas, são tratadas como um novo produto imobiliário, ocupando um espaço periférico antes destinado somente aos que não tinham poder aquisitivo para ocupar os centros das cidades, mas que agora convivem de maneira próxima, sem esquecer que tal convívio que só é possível pelo complexo de muros e guaritas que separam as áreas pobres e de ocupações irregulares, daquelas destinas aos complexos imobiliários de luxo, anulando a convivência entre as diferenças, que é fruto natural do processo de urbanização vivenciado pelas cidades ao longo dos anos.

Ciente desses aspectos, é importante ressaltar que a segregação urbana, é um processo presente entre as classes sociais, porém, o fator em que ambos ocorrem são distintos. É preciso destacar que muitas das pessoas que vivem nessas condições, não são responsáveis e não gostariam de estar vivendo nelas, é uma "imposição" pela qual são forçadas graças as dificuldades de acesso ao solo urbano que se tornou um 
produto que não é acessível a todos. Isso por sua vez contrasta com as famílias de maior poder aquisitivo, que ao comprarem casas em condomínios fechados, optam pela quebra do tecido urbano e pela negação do entorno, o que pode ser entendido como uma "segregação autoimposta", pois foram os mesmos que escolheram viver nessas condições (ZECHIN et al., 2019).

O mesmo pode se dizer de condomínios voltados a programas sociais recentes como os do Minha Casa Minha Vida - MCMV, que muito embora voltados para um segmento popular, as incorporadoras optam pelo que Ferreira (2012), chama de "condomínios-clube", onde são oferecidos intramuros praças, quadras, playgrounds e outras benesses que imitam os condomínios de luxo das classes mais altas, rompendo a malha urbana e optando por um padrão de vida voltado ao uso do automóvel, dada a distância em que esses espaços se encontram dos centros de comércio e de trabalho. No caso das construções de condomínios residenciais fechados, não importa o nível social em que se encontram, seja dos segmentos de menor renda ou de classe média como do programa habitacional público MCMV, ou de empreendimentos particulares voltados ao mercado de luxo, ambos acabam exercendo os mesmos impactos negativos na malha urbana.

Em uma sociedade que não valoriza os investimentos em áreas públicas, apresentando cidades com poucas praças, parques e espaços similares, a "privatização" desses equipamentos é espécie de reflexo de cultura urbana já bastante fragilizada. A privatização dos espaços de lazer e convivência é prática antiurbana, segregadora e que não privilegia a diversidade social dos espaços da cidade. (FERREIRA, 2012)

A segregação sempre foi levada a cabo por motivos específicos, como étnicos e religiosos, esse novo fenômeno da auto-segregação exige uma nova análise sobre os motivos pelos quais isso acontece. A morfologia urbana observada no século XIV e meados do século XX, onde existia uma clara dinâmica territorial de centro bem estruturado versus periferia, é posto à prova com as novas "estruturas multicêntricas", onde cria-se um caráter heterogêneo do espaço das cidades, e a segregação que ainda insiste em persistir, está diretamente ligada com a capacidade de compra de cada indivíduo, tento intima relação com a segregação socioeconômica, se aprofundando gradualmente e extrapolando os limites residenciais, orientando o crescimento econômico na malha urbana, que sempre tente a ser mais estruturada nas áreas onde se concentram pessoas com maior poder aquisitivo (SPOSITO, 2016).

E por esse motivo, Frey et al. (2006), demonstram a complexidade desse tema no Brasil, e apontam para um fator atípico até o momento nas políticas sociais e urbanas. Levando em conta os aspectos da autosegregação, em relação a gestão mais democráticas das cidades, seria necessário não somente uma política voltada para a incorporação social das pessoas excluídas e marginalizadas da sociedade, mas também políticas que incorporem as pessoas que optaram pela reclusão em relação aos espaços das cidades, uma vez que ficou claro a abnegação aos espaços públicos dos quais não são mais necessários para atender as necessidades e seus "interesses particulares". Nesse caso ações mais abrangentes seriam necessárias para mitigar os efeitos da segregação urbana, que combinadas e alinhadas com as mais diversas diferenças sociais que possam existir, busquem mutuamente a concepção de um espaço urbano coletivo, justo e igualitário. 


\section{CONCLUSÕES}

Este artigo teve como objetivo realizar uma revisão teórica da segregação consolidada no solo urbano. Identificamos sob a luz dos autores Hirata (2009), Ferreira (2012), Sposito (2018), Frey et al. (2006), que os agentes causadores pela ruptura dos agrupamentos em comunidades mais carentes ou em situações economicamente mais abastadas estão diretamente relacionados ao poder monetário ou pela falta dele, estando diretamente ligados ao fator capitalista do mercado financeiro. O mercado imobiliário transforma o uso e ocupação do solo urbano em mercadorias. Já as políticas públicas passam a voltar-se as questões relacionadas ao planejamento urbano, a moradia e a morfologia urbana.

Os resultados obtidos nesse estudo teórico, visam elucidar a cidade contemporânea, trazendo fatores relevantes para proporcionar mecanismos que possam combater ou minimizar a segregação urbana.

Esse estudo traz como constatação que a segregação está diretamente relacionada ao poder de compra de cada indivíduo e de como o capitalismo modifica o meio urbano. Os apontamentos dessa abordagem teórica tornam-se perceptíveis quando referenciamos as questões relacionadas as grandes glebas antes rurais que passaram a ser urbanas sendo ponderadas como um produto imobiliário. Outra constatação percebida está relacionada aos condomínios do programa Minha Casa Minha Vida, os quais são oferecidos privilégios que passam a assemelhar com condomínios de classes mais opulentas, esses empreendimentos rompem a malha urbana e criam aspectos relacionados ao uso do automóvel por estarem distantes do centro ou dos locais de trabalho.

As contribuições desse estudo estão relacionadas aos aspectos causados pela ruptura desses agrupamentos em comunidades ou mesmo em condomínios residências de alto padrão, bem como, o comportamento em relação ao entorno dos agrupamentos, seja no perímetro imediato ou em relação a toda a cidade. Destaca-se que este fenômeno está relacionado ao fator monetário, ao fator capitalista gerado pelo mercado financeiro, da mesma forma, as questões de transformações que o mercado imobiliário gera em seu entorno imediato e no uso e ocupação do solo das cidades.

Este estudo limita-se a um discurso teórico com base nos autores Hirata (2009), Ferreira (2012), Sposito (2018) e Frey et al. (2006). Como recomendações para um estudo futuro, seria importante analisar os fatores históricos da segregação relacionando-os com os aspectos tempo, causas e consequências do agrupamento, bem como os padrões de alta renda e baixa renda fazendo uma abordagem por meio de um estudo de caso do perímetro imediato e sua interferência exercida na malha urbana da cidade.

\section{REFERÊNCIAS}

CANETTIERI, T.; PEREIRA, T.; LIBERATO, R. C.. Uma contribuição para o entendimento da segregação urbana: exploração, dominação e valorização. Revista Espinhaço, p.3-13, 2017.

CARLOS, A. F. A.. Da "Organização" à "Produção" do Espaço no Movimento do Pensamento Geográfico. In: CARLOS, A. F. A.; SOUZA, M. L.; SPOSITO, M. E. B.. A produção do espaço urbano: agentes e processos, escalas e desafios. São Paulo: Contexto, 2018, p.124-145.
CORRÊA, R. L.. Segregação residencial: classes sociais e espaço urbano. In: CORRÊA, Roberto Lobato; PINTAUDI, S. M.; VASCONCELOS, P. A.. A cidade contemporânea: segregação espacial. São Paulo: Contexto, 2016, p.39-59.

DEL RIO, V.; SIEMBIEDA, W.. Desenho Urbano

Contemporâneo no Brasil. Rio de Janeiro: LTC, 2019. 
FERREIRA, J. S. W.. Produzir casas ou construir cidades. Desafios para um novo Brasil urbano. São Paulo: FAPUM, 2012.

FREY, K.; DUARTE, F.. Auto-segregação e a Gestão das Cidades. Ciências Sociais em Perspectiva. Cascavel, v.5. n.9, p.109-119, 2006.

HIRATA, F.. "Minha Casa Minha Vida": Política de Habitacional de Geração de Emprego ou Aprofundamento da Segregação Urbana? Aurora: Revista PPGCSV Unesp, Marília, v.2, n.2, p.01-11,2009. Dol: https://doi.org/10.36311/1982-8004.2009.v2n2.1202

LAGO, L. C.. Favela-loteamento: Reconceituando os Termos da llegalidade e da Segregação Urbana. Cadernos Metrópole, São Paulo, n.4, p.119-133, 2003.

MEDEIROS, C. R. O.; VALADÃO JÚNIOR, V. M.; FERREIRA, A. P.. Condomínios Horizontais Fechados: segregação do espaço social. Revista Eletrônica de Administração, v.11, 2008.

MOREIRA JÚNIOR, O. M.. Cidade Partida: Segregação Induzida e Auto-segregação Urbana. Caminhos da Geografia, Uberlândia, v.13, n.33, p.1-10, 2010.

PADUA, R. F.. Espaços de Desindustrialização na Urbanização Contemporânea da Metrópole. In: CARLOS, A. F. A.. Crise Urbana. São Paulo: Contexto, 2018, 85-103.
POMBO, R.. Dicionário de Sinônimos da Língua Portuguesa. 2 ed. Rio de Janeiro: Academia Brasileira de Letras, 2011.

RIBEIRO, F. V.. Produção Contraditória do Espaço Urbano e Resistências. In: CARLOS, A. F. A.. Crise Urbana. São Paulo: Contexto, 2018. p.171-186.

SPOSITO, M. E. B.. A produção do espaço urbano: escalas, diferenças e desigualdades socioespaciais. In: CARLOS, A. F. A.; SOUZA, M. L.; SPOSITO, M. E. B.. A produção do espaço urbano: agentes e processos, escalas e desafios. São Paulo: Contexto, 2018. p.123-145.

SPOSITO, M. E. B.. Segregação Socioespacial e Centralidade Urbana. In: CORRÊA, R. L.; PINTAUDI, S. M.; VASCONCELOS, P. A.. A cidade contemporânea: segregação espacial. São Paulo: Contexto, 2016, p. 17-37.

VASCONCELOS, P. A.. Contribuição para o debate sobre processos e formas socioespaciais nas cidades. In: CORRÊA, R. L.; PINTAUDI, S. M.; VASCONCELOS, P. A.. A cidade contemporânea: segregação espacial. São Paulo: Contexto, 2016, p. 17-37.

ZECHIN, P.; HOLANDA, F. R. B.. Atributos espaciais da desigualdade nas grandes cidades brasileiras: uma relação entre segregação e morfologia. Caderno Metrópoles, São Paulo, v.21, n.44, p.55-78, 2019.

A CBPC - Companhia Brasileira de Produção Científica (CNPJ: 11.221.422/0001-03) detém os direitos materiais desta publicação. Os direitos referem-se à publicação do trabalho em qualquer parte do mundo, incluindo os direitos às renovações, expansões e disseminações da contribuição, bem como outros direitos subsidiários. Todos os trabalhos publicados eletronicamente poderão posteriormente ser publicados em coletâneas impressas sob coordenação da Sustenere Publishing, da Companhia Brasileira de Produção Científica e seus parceiros autorizados. Os (as) autores (as) preservam os direitos autorais, mas não têm permissão para a publicação da contribuição em outro meio, impresso ou digital, em português ou em tradução. 